\title{
DEVELOPMENT OF CULTURED PEARL CIRCLES AND SHAPE AFTER INITIAL GRAFT AND SECOND NUCLEUS INSERTION IN THE BLACK-LIPPED PEARL OYSTER PINCTADA MARGARITIFERA
}

\author{
CHIN-LONG KY, ${ }^{1 *}$ JONATHAN DEMMER, ${ }^{1}$ MANAARII SHAM-KOUA ${ }^{1}$ AND \\ PHILIPPE CABRAL ${ }^{2}$ \\ ${ }^{1}$ Ifremer, UMR EIO241, Labex Corail, Centre du Pacifique, BP 7004, 98719 Taravao, Tahiti, French \\ Polynesia; ${ }^{2}$ Gauguin's Pearl Farm, BP 191, 98776 Avatoru, Rangiroa, Archipel des Tuamotus, French \\ Polynesia
}

\begin{abstract}
Production of larger, rounder, high-quality cultured pearls with fewer circles is one of the main challenges of Pinctada margaritifera aquaculture faced by every pearl farm in French Polynesia. Although bigger pearl sizes can be achieved through surgreffe operations (implantation of a second nucleus after pearl harvest), control of the development of pearl circles and shapes still remains unclear, as illustrated by grafter's empirical rules, where often the surgreffe process is only performed after production of uncircled and round pearl shapes. The present study was designed with a real pearl by pearl traceability to reveal for the first time the development of circles and shapes from graft and surgreffe, in relation to the size of the pearl sac. This was indirectly assessed by measuring the differences in diameter (DD) and weight (DW) between standardized surgreffe nuclei and the pearl that had been harvested after the initial graft. An experimental graft and surgreffe experiment was designed using the same criteria: grafter, location, nuclei brand and size for graft and surgreffe, and donor oysters from 10 biparental families produced in a hatchery system. We studied the differences between pearls harvested after graft and surgreffe on the same recipient oysters $(n=295$ for both graft and surgreffe) in relation to three classes of DD and DW in which the surgreffe nuclei, were: (1) bigger/heavier, (2) equivalent to, or (3) smaller/lighter than the harvested pearl. Results revealed that to increase the rate of uncircled pearls after surgreffe, insertion of a nucleus larger than the harvested pearl may be advisable. Indeed, the formation of uncircled pearls after surgreffe was enhanced by inserting bigger/ heavier second nucleus, both in animals that had produced a uncircled pearl after the initial graft and in those that had produced a circled pearl. For pearl shape, significantly more round shape pearls were produced after surgreffe, after initial oval and baroque samples from graft, by inserting smaller/lighter and bigger/heavier second nucleus, respectively. Inserting a larger second nucleus will significantly increase the rate of both uncircled and round-shaped pearls. This finding has important implications for surgreffe practices, where recipient oysters with undesirable circle or baroque pearls could now be used in this second stage of production.
\end{abstract}

KEY WORDS: pearl oyster, Pinctada margaritifera, surgreffe, circled pearls, pearl shapes, pearl sac

\section{INTRODUCTION}

The mollusc Pinctada margaritifera var. cumingi is the most economically important aquaculture species in French Polynesia. Although P. margaritifera is particularly abundant in the atolls of French Polynesia (Strack 2006), it is found throughout the coral areas of the Indo-Pacific. The aquaculture of this species, commonly called the black-lipped "pearl oyster", represents the second highest economic activity after tourism in French Polynesia. Income from the exportation of pearls has been, however, fallen by $33 \%$ since 2006 (Talvard 2011) as a result of: (1) overproduction; (2) decrease in pearl quality; and (3) a worldwide economic crisis. First, overproduction has had a direct impact on pearl value, which has fallen from 1,393 to 470 CFP per gram (Du Prel 2012). Second, in the past decade, the average quality and size of cultured pearls have decreased, as shown by the $50 \%$ increase in the number of valueless pearls being destroyed (250 kg in 2009 and $400 \mathrm{~kg}$ in 2010) (Talvard 2011, Wane 2013). This was a direct consequence of overproduction, which favored quantity over quality, through reduction of culture time. In fact, in French Polynesia, the export of cultured pearls is strictly controlled: pearls must have a nacreous layer with a minimum thickness of $0.8 \mathrm{~mm}$ built up on the nucleus or else they must be destroyed. Production of high-quality cultured pearls is consequently a major challenge for pearl farmers

*Corresponding author. E-mail: chinky@ifremer.fr DOI: $10.2983 / 035.034 .0214$
(Tayale et al. 2012, Ky et al. 2013). They must: (1) reduce the environmental and economic costs associated with overproduction; and (2) increase the quality of harvested pearls. Indeed, the average of quality cultured pearls is lower than it was a decade ago (Blay et al. 2013). Today, pearl production is conducted on 26 atolls and islands in French Polynesia, with 536 pearl farms, covering nearly 7,800 ha of maritime concessions.

Among all the parameters of cultured pearl quality, "circles" and shape are the most important criteria determining pearl value (Taylor \& Strack 2008). A circled pearl (CL) corresponds to the development of one or several visible concentric rings or grooves on the pearl's surface. Circles are not specific to a particular shape of pearl in Pinctada margaritifera. Murzyniec-Laurendeau (2002) showed that in a sample harvest of 271,000 P. margaritifera cultured pearls from French Polynesia (Tuamotu Archipelago), circled samples accounted for $23 \%$ of the volume but only $6 \%$ of the value. For pearl shape (with all other factors being equal: weight, size, color, and lustre), three major categories are present, from the most to the least valuable: (1) round/semiround pearls ("R"); (2) button, drop or oval ("O"); and (3) baroque sample ("B") (Ky et al. 2013). Average proportions found in an experimental graft from $P$. margaritifera were $47.0 \%(n=411)$ of "R" shape, $41.5 \%(n=363)$ of "B" shape and $11.4 \%$ of "O" shape. In a more recent study in the Gambier Archipelago, an average of $12 \%$ of $\mathrm{R}$ shape was found in a harvest sample of 42,575 pearls (Ky et al. 2015). In general, " $R$ " shapes are the most valuable compared with other common shapes ("B" and "O"), which are less valuable (for 
the same quality). The most valuable cultured pearls correspond to the combination of uncircled and round pearls, which only represent $5 \%$ of the whole $P$. margaritifera pearl production (source: Institut Statistique de la Polynésie Française [ISPF]). Statistical data from the $11^{\text {th }}$ Cooperative Tahiti Auction (November 2014) showed the average price of " $R$ " cultured pearls from the A-B quality grade (according to the official A-D classification: see Journal Officiel 2001, no. 30, 26 July 2001) to be close to 42 euros per gram.

Cultured Tahitian pearl production is based on a surgical operation, which consists of introducing a round nacreous bead (nuclei are made from the shell of a freshwater mussel from the Mississippi River) into the gonad of a "recipient" oyster, together with a small piece of mantle tissue (the graft of $\sim 4 \mathrm{~mm}^{2}$ ) from a dissected "donor" oyster (Kawakami 1952, Haws 2002). A pearl sac is formed during the next few weeks by cellular multiplication of the graft cells (Machii 1968, Inoue et al. 2011). Cultured pearl formation occurs by successive deposit of nacre layers around the nucleus, corresponding to the biomineralization property of the mantle tissue (Cuif \& Dauphin 1996). After 15-18 mo of culture, the pearls are harvested. Usually, the recipient oysters that produce pearls fitting the criteria for good quality may be seeded with another nucleus of the same size as the harvested pearl to produce bigger pearls during a subsequent culture period. This second operation is called the surgreffe; another graft insertion is not needed as the pearl sac is already established (Sarikaya et al. 1995, Lane et al. 2003). Surgreffe operations remain the most popular way to improve pearl size and weight in oyster aquaculture, which can also be increased by increasing the cultured time and the age (size) of the recipient oyster. Currently, surgreffe operations concern around $30 \%$ of oysters from which pearls are harvested after the initial graft and the process can be repeated successively three to four times (Le Pennec \& Buestel 2010).

The reasons for the development of pearl circles and different pearl shapes after graft and surgreffe in Pinctada margaritifera remain unclear. Each pearl farm has its own experience and empirical "rules" for their protocol; for example, whether or not a grafter realizes a surgreffe on a pearl oyster after harvesting an undesirable circled or nonround pearl. The formation of pearl shapes from graft and surgreffe has yet to be studied with real traceability avoiding the influences of genetic and environmental variation. To ensure such traceability, an analysis was made of pearls produced from surgreffe of the recipient oysters that had initially been grafted using specific donor oyster families and whose first harvested pearls had already been examined by Ky et al. (2013) after culture in a single site. From a practical point of view, the present study could change the criteria influencing a grafter's decision, based on pearl circles and shapes at harvest, on whether to perform a surgreffe operation to obtain a second pearl from the same oyster.

\section{MATERIALS AND METHODS}

\section{Pearl Oysters and Surgreffe Procedure}

Ten biparental families of Pinctada margaritifera, produced in the Ifremer hatchery facilities in Vairao (Tahiti, French Polynesia), were used in a graft experiment (Ky et al. 2013). A number of the same recipient oysters were used for the present surgreffe operation (Fig. 1). To minimize environmental effects, the surgreffe experiment was done: (1) at a single grow-out site at Rangiroa atoll $\left(15^{\circ} 07^{\prime} \mathrm{S}, 147^{\circ} 38^{\prime} \mathrm{W}\right.$, Tuamotu Archipelago, French Polynesia); (2) at the same pearl farm (Gauguin's Pearl

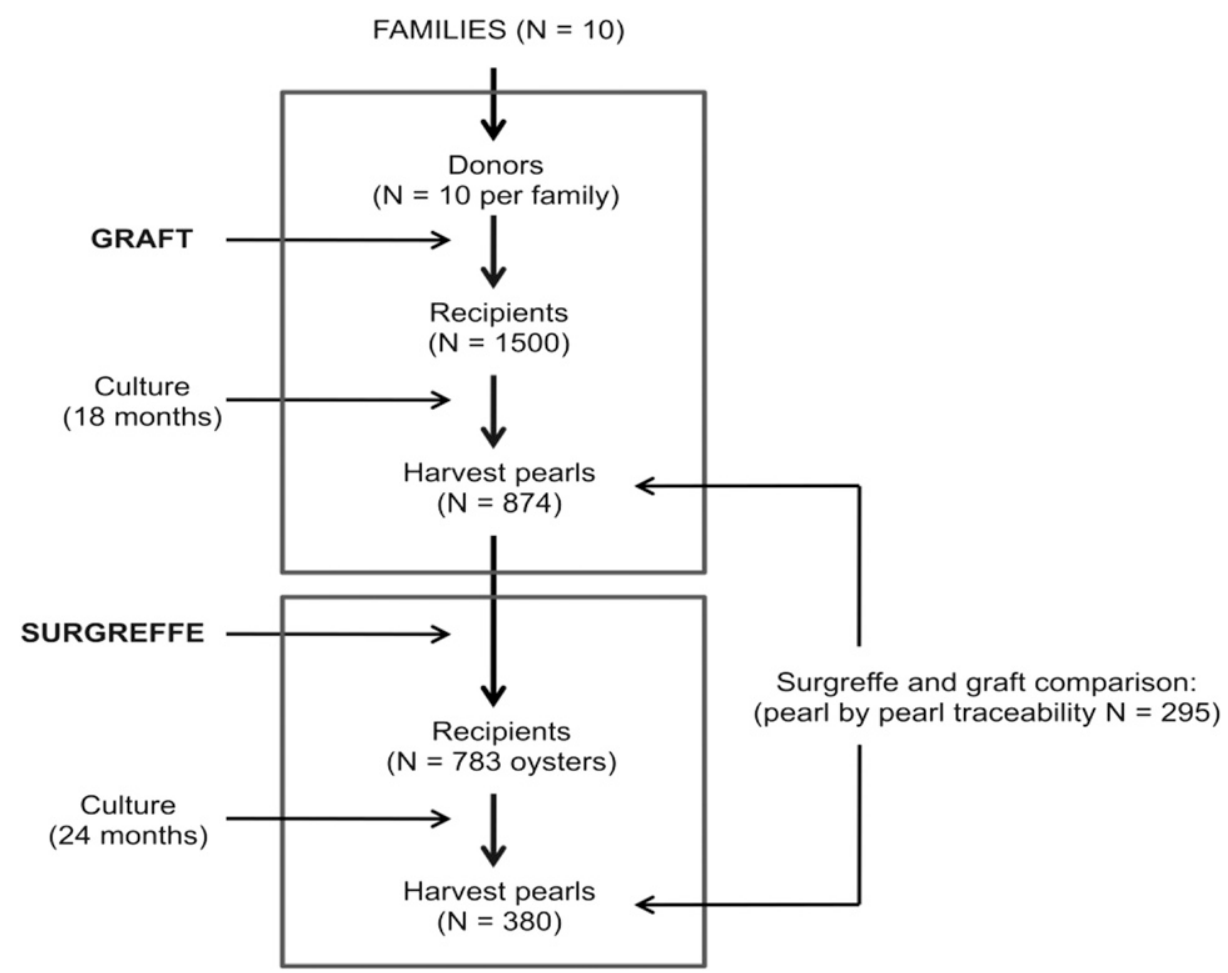

Figure 1. Experimental design of the surgreffe procedure after experimental graft (from Ky et al. 2013). Surgreffe operation was performed in Rangiroa atoll (Tuamotu archipelago). 
Farm) with the same professional grafter to minimize grafter effects (the same grafter who made the graft operations described by Ky et al. 2013); and (3) with the same size and brand of nucleus: 3.5 BU nucleus (10.48 mm diameter and $1.84 \mathrm{~g}$ weight Nucleus Hyakusyo Co., Japan). This first surgreffe nucleus size was chosen because it is the average size and the most frequently used for the first surgreffe operation on this farm. Not all of the initially grafted oysters can be considered for surgreffe after harvest, due to mortality or nucleus rejection during culture or if their shells were broken by forced opening during pearl harvest. Therefore, 783 recipient oysters were used for surgreffe during the experiment in April 2012. After the surgreffe operations, the recipient oysters were put in batches of 10 on a chaplet and protected by a plastic mesh to avoid predation (Ky et al. 2013). During the culture period, the surgreffe oysters were cleaned every 6 mo using high-pressure sea water (Kärcher).

\section{Measurement of Cultured Pearl Circles and Shape}

After 24 mo of culture, the sample pearls were harvested and placed into a compartmented box that allowed traceability between sample and corresponding donor oysters. Some keshi (small irregular-shaped nacreous but nonnucleated pearls that form during the culture time after nuclei have been rejected) could also be harvested, but not graded. Cultured pearls were then cleaned by ultrasonication in soapy water (hand washing) with a LEO 801 laboratory cleaner (2-L capacity, $80 \mathrm{~W}, 46 \mathrm{kHz}$ ) according to the study by Ky et al. (2013).

Pearls with circled nacre were evaluated by the presence or absence of concave ring(s) around the cultured pearl. A single operator determined visually (without a loupe) if harvested pearls presented circle(s) (C) or not (NC), whatever their shape category. The cultured pearls that presented colored circles but not hollows were counted as uncircled pearls.

The shape of cultured pearls was also determined visually by one operator, on three categories ( $\mathrm{R}, \mathrm{O}$, and $\mathrm{B}$ shapes) as described by Ky et al. (2014a).

\section{Measurement of Diameter and Weight Differences}

To understand the relationship of the size and weight of the first pearls harvested after grafting with the size and weight of a standard nucleus inserted at surgreffe, and the impact that such differences may have on subsequent second pearls issued from surgreffe, estimations were made of the difference in diameter (DD) and difference in weight (DW) for each of the shape categories (circled, uncircled, round, oval, and baroque). Then, three classes were derived for each shape group based on: (1) size: small ( $\mathrm{DD}<0 \mathrm{~mm})$, near equivalent $(\mathrm{DD}=0-1 \mathrm{~mm})$, and large (DD $>1 \mathrm{~mm}$ ); and (2) weight: light ( $\mathrm{DW}<0 \mathrm{~g})$, near equivalent $(\mathrm{DW}=0-0.5 \mathrm{~g})$, and heavy ( $\mathrm{DW}>0.5 \mathrm{~g}$ ).

The difference between the harvested pearl diameter from the initial graft and the standard nucleus diameter used for surgreffe $(10.47 \mathrm{~mm})$ was assessed using the formula: diameter difference $(D D)=10.47-($ cultured pearl diameter harvested from graft); the cultured pearl diameter from initial graft and the nucleus diameter were measured by scanning the pearls with an Epson perfection V750 Pro, then treating the images using Adobe Photoshop CS3 and Image J.

The difference between the weight of harvested pearls issued from the initial graft and the standard nucleus weight used for surgreffe $(1.842 \mathrm{~g})$ was calculated using the formula: weight difference $(\mathrm{WD})=1.842-$ (cultured pearl weight harvested from graft); cultured pearl weight from graft and nucleus weight were weighed using an Excellence Plus digital balance (Mettler, Toledo; $0.1 \mathrm{mg}$ precision).

\section{Statistical Analysis}

From the 783 pearl oysters that underwent surgreffe operations, 380 cultured pearls were harvested among the 10 families. This sample was used for surgreffe family effect analysis, using a Chi-square test for both circle and shape variables (Siegel \& Castellan 1988, Winer et al. 1991).

Of the 380 cultured pearls harvested, 295 allowed pearl-bypearl traceability from the graft experiment (Ky et al. 2013) to the present surgreffe experiment. These 295 paired samples made it possible to perform the following statistical analyses.

Comparison between graft and surgreffe for the 295 harvested and traceable pearls was performed using a McNemar Chisquare test for each of the circle classes (circled and uncircled). To evaluate the comparison of the shapes between harvested pearls from graft and surgreffe, a Friedman test was used (Hutchinson 1996). The same test was used for an interfamily scale comparison between graft and surgreffe for circled and shape variables.

A Chi-square test was used to compare the 295 harvested and traceable pearls between graft and surgreffe for all variables. Then a Kruskall-Wallis test followed by Dunn's multiple comparison procedure was used to estimate the impact of DD and DW classes on the development of samples from graft harvest to surgreffe for all variables.

All tests were performed using XLSTAT (version 2009.4.02) and $P$ values lower than 0.05 were considered significant (Dagnelie 2007).

\section{RESULTS}

\section{Cultured Pearl Circles}

Of the 380 harvested pearls from the first surgreffe, the overall rate of uncircled samples was $60.0 \%(n=228)$, with minimum and maximum values of $46.9 \%$ (Family E, $n=15$ among 32 harvested pearls) and $75.5 \%$ (Family A, $n=40$ among 53 harvested pearls), respectively. The corresponding average rate of circled samples was $40.0 \%(n=152)$. No significant donor family effect was observed for the presence/absence of circles in pearls from surgreffe, $P=0.232$. Family ranking from most to least amount of uncircled pearls was: A, F, B, I, J, G, C, D, H, and E (Fig. 2).

Comparison between surgreffe and graft results $(n=295)$ revealed a highly significant difference $(P=0.008)$ for the average uncircled rate, with $65.1 \%$ and $75.6 \%$, respectively. Thus, the trend was a decrease in uncircled pearls from graft to surgreffe. Considering the families separately, significant differences were found for the numbers of uncircled pearls between graft and surgreffe, except for families B $(P=0.047)$ and D $(P=0.039)$. For these two families, the average percentage of uncircled pearls decreased from graft to surgreffe: $-20.7 \%$ and $-25.8 \%$ for families B and D, respectively (Fig. 2).

The change in the proportion of uncircled (and circled) pearls between graft and surgreffe showed a very highly significant effect $(P<0.0001)$. Of the group that produced uncircled pearls after the initial graft $(n=223)$, nearly two-thirds produced uncircled pearls from surgreffe $(n=144)$, with one-third 


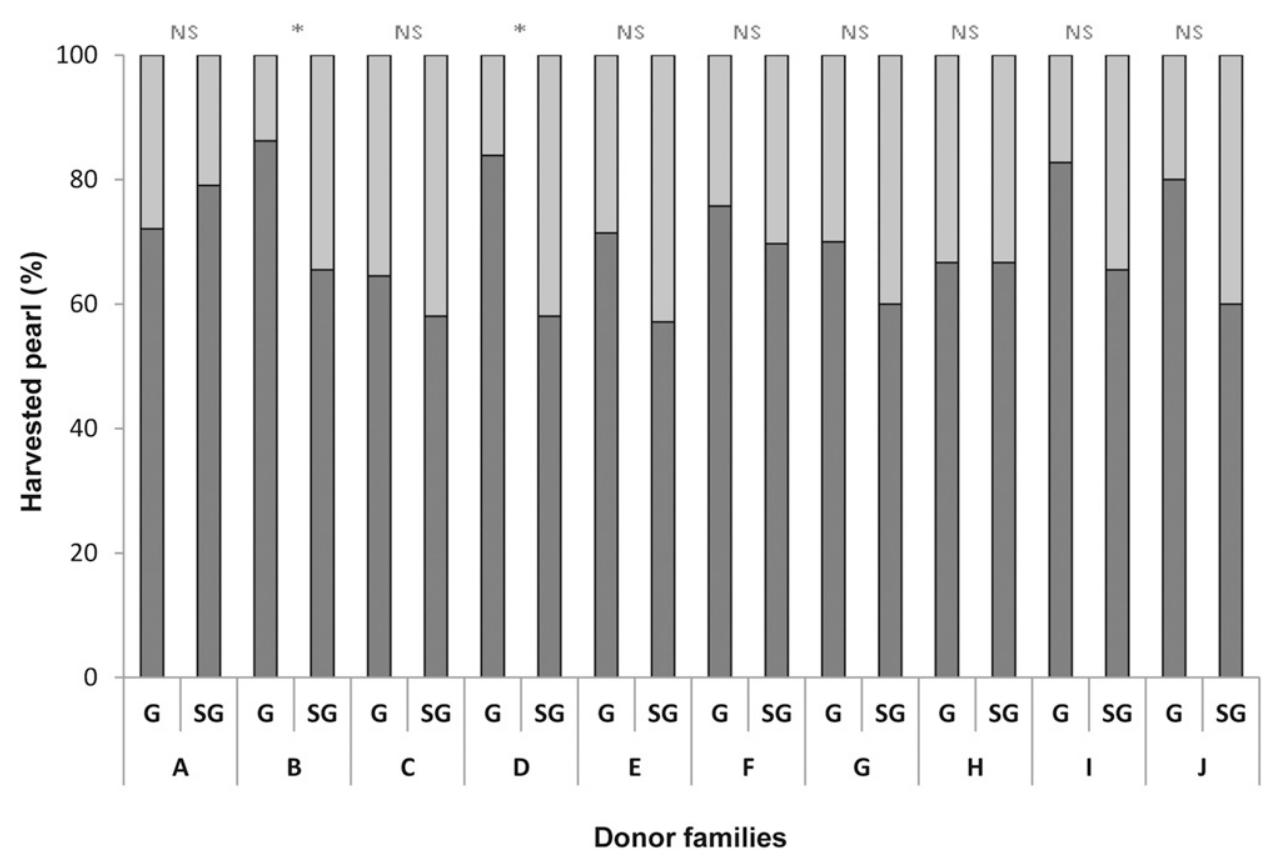

Figure 2. Cultured pearl circle rate (in \%) from graft (G) and surgreffe (SG) for each of the Pinctada margaritifera donor families (A to J). Histogram sections represent: (1) in dark grey, uncircled pearls; and (2) in light grey, pearls with circle/s. Significant differences between graft and surgreffe are noted as follows: NS, nonsignificant $(P>0.05)$; and *, significant $(P<0.05)$.

producing CLs (Table 1 ). In addition, two-thirds of the oysters having produced CLs from their initial graft $(n=72)$ produced uncircled pearls $(n=48)$ after surgreffe (with one-third remaining circle) (Table 1).

The number of uncircled pearls produced from surgreffe by animals that had already yielded a uncircled pearl after the initial graft increased from the smallest DD class (diameter difference between nucleus inserted for surgreffe and pearl harvested after the graft) to the largest: $14 \%$ (Table 2). Inversely, the rate of CLs in surgreffe produced by oysters that had yielded uncircled pearls from graft) decreased following the DD classes, from the smallest to the largest. In addition, when CLs were harvested from graft, the rate of change to uncircled pearls at surgreffe in the same animals increased with increasing DD class: $30 \%$ from the smallest class to the largest. By contrast, the rate of CLs produced by surgreffe in oysters that had originally yielded CLs after the initial graft decreased with DD class, from the smallest to the largest (Table 2). Statistical analysis revealed three significantly different groups $(P=0.022)$ : $(1)$ oysters that produced uncircled pearls from the initial graft, but CLs following surgreffe; (2) pearls that did not change from graft to surgreffe; and (3) animals that yielded CLs after the graft but uncircled pearls after surgreffe. The same trends were observed for DW classes (WD between nuclei inserted at surgreffe and the pearls harvested after the initial graft) as with the DD classes. The same three groups were significantly different $(P=0.029)$ for the DW classes as for the DD classes.

\section{Cultured Pearl Shape}

Of the 380 harvested pearls obtained from the surgreffe, the average rate of " $\mathrm{R}$ " shape was $27.4 \%(n=104)$, with minimum and maximum values of $12.5 \%$ (Family $\mathrm{E}, n=4$ among 32 harvested pearls) and $43.4 \%$ (Family A, $n=23$ among 53 harvested pearls), respectively. The average rate of "O" shape was $23.7 \%(n=90)$, with minimum and maximum values of $10.3 \%$ (Family $\mathrm{B}, n=3$ among 29 harvested pearls) and 32.3\% (Family G and I, $n=11$ among 34 harvested pearls for each), respectively. The corresponding average rate of " $\mathrm{B}$ " shape was $48.9 \%(n=186)$, with minimum and maximum values of $35.8 \%$ (Family A, $n=19$ among 53 harvested pearls) and $75.0 \%$ (Family E, $n=24$ among 32 harvested pearls), respectively. No significant donor family effect was observed for the shapes of pearls from surgreffe, $P=$ 0.060 . Family ranking from those showing most to the least " $R$ " shapes was: A, D, C, F, B, H, I, J, G, and E (Fig. 3).

Comparison between surgreffe and graft results for " $\mathrm{R}$ " shape revealed a very highly significant effect $(P<0.0001)$ with $31.2 \%$ and $48.8 \%$, respectively. Thus, the trend from graft to surgreffe was a decrease in the number of " $R$ "-shaped pearls. Individually, only three families showed significant differences for the rate of " $\mathrm{R}$ "-shaped pearls between surgreffe and graft: $\mathrm{E}(P=0.040), \mathrm{H}(P=0.046)$, and $\mathrm{J}(P=0.008)$. For these three families, the average percentage of " $\mathrm{R}$ "-shaped pearls decreased from graft to surgreffe: $-28.6 \%,-24.2 \%$, and $-31.4 \%$ for families E, H, and J, respectively (Fig. 3). For "O" shape, overall comparison between surgreffe and graft showed a highly significant difference $(P=0.001)$ with $20.3 \%$ and $10.8 \%$, respectively. Thus, the tendency from graft to surgreffe was an increase of "O" shapes. The only significant difference observed at an interfamily scale was for family I $(P=0.003)$, which produced $31.0 \%$ of "O" shape on surgreffe (Fig. 3). Comparison of " $\mathrm{B}$ " shape between surgreffe and graft revealed a significant difference $(P=0.047)$, with $48.5 \%$ and $40.3 \%$, respectively. No significant difference was, however, observed at an interfamily scale for any of the donor families considered individually (Fig. 3).

The difference in the shape of the pearls formed at graft and surgreffe showed a very highly significant difference $(P<0.0001)$ 
TABLE 1.

Cultured pearl circles development after graft and surgreffe. Two variables are presented: (1) uncircled pearls; and (2) circled pearls, with their corresponding number and rate $(\%)$ in brackets.

\begin{tabular}{|c|c|c|c|}
\hline \multirow[b]{2}{*}{ Circle presence on pearl harvested following graft } & \multirow[b]{2}{*}{ Total pearls from graft } & \multicolumn{2}{|c|}{ Development following surgreffe } \\
\hline & & Uncircled & Circled \\
\hline \multicolumn{4}{|l|}{ Uncircled } \\
\hline & 223 & $144(64.6)$ & $79(35.4)$ \\
\hline \multicolumn{4}{|l|}{ Circled } \\
\hline & 72 & $48(66.7)$ & $24(33.3)$ \\
\hline
\end{tabular}

for the frequencies of the "R," "O," and "B" shapes. Of the oysters that produced an " $\mathrm{R}$ " shape pearl after the initial graft ( $n=144)$, (1) nearly one-third produced an " $\mathrm{R}$ "-shaped pearl again after surgreffe $(n=45)$; (2) one-fifth produced "O'"-shaped pearls $(n=29)$; and (3) nearly half produced " $\mathrm{B}$ "'-shaped pearls $(n=70)$ (Table 3$)$. For "O" shape, only $12.5 \%$ produced an "O" shape after both graft and surgreffe. By contrast, $43.7 \%$ became "R" and "B" at surgreffe in equal proportions (Table 3). For "B" shape, most of the samples (nearly half) remained " $B$ " shape from graft to surgreffe in our experiment. By contrast, nearly a quarter changed to " $\mathrm{R}$ " and another quarter to "O" (Table 3).

Following the difference in weight (DW), the maintenance of " $R$ " shape from graft to surgreffe remained constant (near $30 \%$ ) from the smallest DW class to the largest (Table 4). The individuals that produced "O" shape at graft but " $\mathrm{R}$ " at surgreffe, however, decreased from the smallest DW class to the largest: $-30 \%$ (Table 4). For "B" shape, the trend was an increase of " $R$ " shape between graft and surgreffe as DW classes became larger: nearly $13 \%$ from the smallest to the largest (Table 4). The same observation was found when the DD classes were considered (data not shown).

\section{DISCUSSION}

Prior to this study, no data existed on surgreffe effect or its comparison with corresponding graft effect on cultured pearl circles and shapes in Pinctada margaritifera. To our knowledge, this is the first study of its kind to: (1) evaluate the development of cultured pearl circles and shapes at surgreffe, with a real traceability corresponding to the results of the initial graft (Ky et al. 2013); and (2) demonstrate the correlation between the indirect estimation of the size of the pearl sac and the resulting pearl circles and shapes issued from surgreffe.

\section{Differences in Pearl Circle Incidence Between Initial Graft and Surgreffe in Pinctada margaritifera}

From a descriptive point of view, results showed that from graft to surgreffe, there was a significant decrease $(-15 \%)$ of uncircled harvested pearls. This could not be attributed to grafter skills and/or seasons, which have been shown elsewhere to significantly impact the presence or absence of circles on pearls after an initial graft (Ky et al. 2014b). Indeed, the grafter who operated in this experiment was the same person who operated during the graft experiment (Ky et al. 2013). Furthermore, harvest of cultured pearls after surgreffe and initial graft was performed during the same season of the year. The decrease could partially be explained by the fact that, during our experimental surgreffe operation, the grafter inserted a standardsized second nucleus (3.5 BU) into the pearl sac, whereas second nucleus size is usually chosen in relation to the size of the harvested pearl in usual farm procedure. In addition, this experimental surgreffe operation, using donor families produced by the hatchery system, revealed no significant family effect for circle criteria at surgreffe. This result is consistent with that obtained for the presence or absence of circles after the initial graft (Ky et al. 2013). 
TABLE 2.

The development of circled and uncircled pearls after graft and surgreffe, with their corresponding number and rate (\%) in brackets, in relation to the difference between the nucleus diameter used for surgreffe and the harvested pearl diameter from graft, DD (in mm).

\begin{tabular}{|c|c|c|c|c|}
\hline & & \multicolumn{3}{|c|}{ DD class } \\
\hline & & $\begin{array}{c}\text { Smaller } \\
<0\end{array}$ & $\begin{array}{c}\text { Equivalent } \\
0-1\end{array}$ & $\begin{array}{c}\text { Larger } \\
>1\end{array}$ \\
\hline Graft & Uncircled & 28 & 122 & 73 \\
\hline Surgreffe & Uncircled & $16(57.1)$ & $76(62.3)$ & $52(71.2)$ \\
\hline Graft & Circled & 9 & 27 & 36 \\
\hline Surgreffe & Uncircled & $4(44.4)$ & $17(63.0)$ & $27(75.0)$ \\
\hline
\end{tabular}

The development of circles shows that two-third of the individuals producing uncircled pearls after the graft also produced uncircled pearls at surgreffe. A more noteworthy finding is that, after CLs were harvested after the graft, the same individuals could produce uncircled pearls at surgreffe; this pattern was shown by two-thirds of the animals that produced CLs after the graft. These results could have major implications for the common empirical rule (farmers' pers. comm.) that states that surgreffe operations may only done on animals that have produced uncircled pearls from the graft. If this rule was used in this experiment, 25\% (48 from 192 samples) of uncircled pearls would be lost from the surgreffe harvest.

Pearls harvested from the initial graft were smaller in diameter and lighter in weight on average $[87.46 \%(n=258)$ and $88.81 \%(n=262)$, respectively] than the second inserted nucleus in the pearl sac. The difference of the diameter (DD classes) and weight (DW classes) between the harvested pearls from graft and the second nucleus may be determinant for the formation of circles. Considering the advantages for the pearl industry in the light of these findings, two major points emerge. First, when uncircled pearls were harvested after the initial graft, the maintenance of this desirable characteristic for the pearls produced from surgreffe increased significantly between the class in which the harvested pearl and new nucleus were of equivalent size and the class in which the second nucleus was larger (14\%). Second, for the oysters that yielded CLs from the initial graft, their production of uncircled pearls at surgreffe increased significantly in relation to the increase of DW class, with $38 \%$ from the lightest class to the heaviest (data not shown). Ito (2011) suggested that the formation of circles on the harvested pearls was the result of the pearl sac spatial conformation. In other words, the correspondence between the size of the second nucleus inserted and the size of the pearl sac, assessed here indirectly by the DD and WD classes, had a significant impact on whether pearl circles developed after surgreffe. Indeed, uncircled pearls from surgreffe were greater in number with increasing DD class, both in individuals that had yield uncircled pearls from the graft and in those that had previously produced CLs. If DD was large (i.e., the second nucleus inserted was bigger than the harvested pearl from graft), the pearl sac tension/pressure onto the pearl under formation during the surgreffe culture period could be greater than with a small DD (i.e., when the second nucleus inserted was smaller than the first pearl harvested after the initial graft), thus resulting in no circle formation. The degree of possibility for a pearl to move or rotate during formation inside the pearl sac could therefore influence the formation of circles (Cartwright et al. 2013). Thus, insertion of a nucleus larger than the harvested pearl in the pearl sac could reduce circle formation by reducing pearl movement. By contrast, insertion of a smaller nucleus than the harvested 


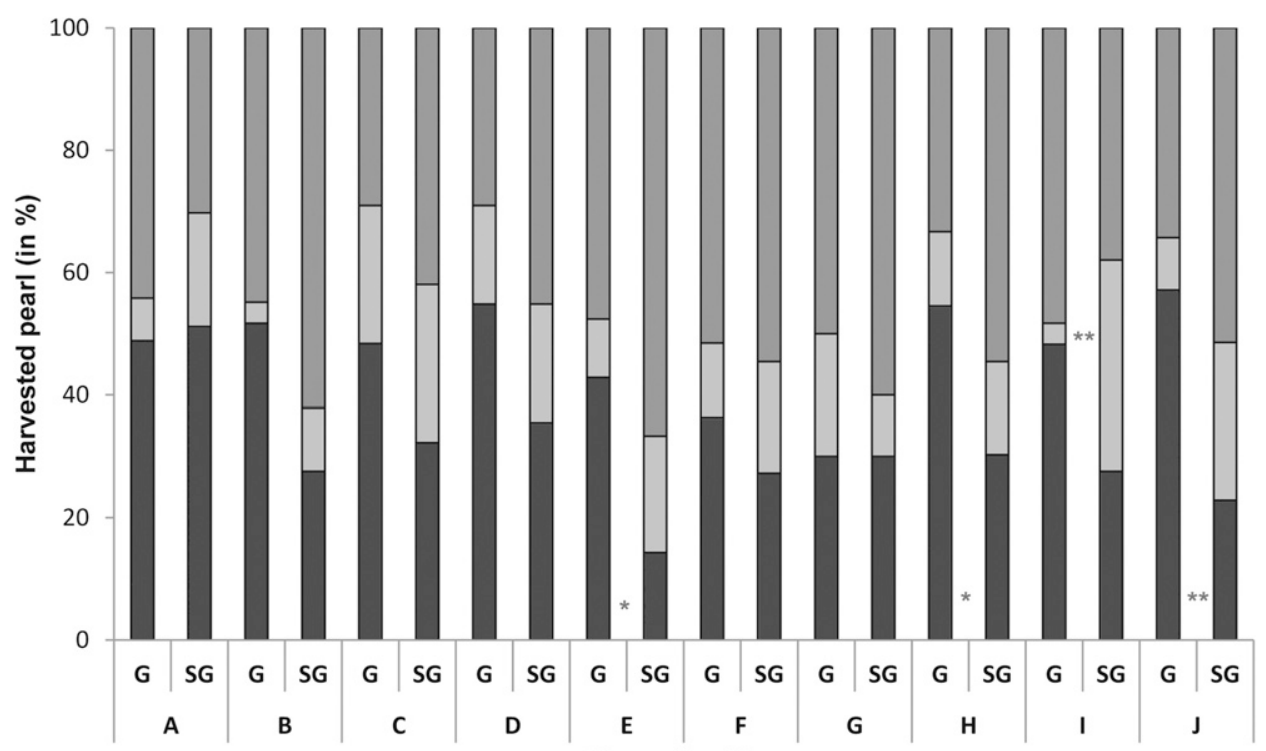

Figure 3. Cultured pearl rate (in \%) for round shape (R), oval shape (O) and baroque shape (B) from graft (G) and surgreffe (SG) for each of the $P$. margaritifera donor families (A to J). Histograms sections colored: (1) in dark grey, pearls with $\mathrm{R}$ shape; (2) in light grey, pearls with $\mathrm{O}$ shape; and (3) in medium grey, pearls with $B$ shape. Significant differences between graft and surgreffe are noted as follows: NS, nonsignificant $(P>0.05)$; *; significant $(P<0.05)$; and $* *$, very significant $(P<0.01)$.

pearl in the pearl sac could have the opposite effect by increasing pearl movement. This could be reflected in our results by the fact that no significant difference for pearl circles was observed between graft and surgreffe in eight donor families
(A, C, E, F, G, H, I, and J), but occurred in the remaining two (B and D). These two families used as donors produced both: (1) more CLs at surgreffe than at graft ( $21 \%$ for B and $25 \%$ for D); and (2) the largest (10.1 $\mathrm{mm}$ for $\mathrm{B}$ and $9.8 \mathrm{~mm}$ for D) and

\section{TABLE 3.}

The development of cultured pearl shapes after graft and surgreffe. Three variables are presented: (1) round shape (R); (2) oval shape (O); and (3) baroque shape (B), with their corresponding number and rate (\%) in brackets.

\begin{tabular}{|c|c|c|c|c|}
\hline \multirow[b]{2}{*}{ Shape } & \multirow[b]{2}{*}{ Total pearls from graft } & \multicolumn{3}{|c|}{ Development following surgreffe } \\
\hline & & $\mathrm{R}$ & $\mathrm{O}$ & B \\
\hline \multicolumn{5}{|l|}{$\mathrm{R}$} \\
\hline & 144 & $45(31.2)$ & $29(20.1)$ & $70(48.6)$ \\
\hline \multicolumn{5}{|l|}{$\mathrm{O}$} \\
\hline & 32 & $14(43.7)$ & $4(12.5)$ & $14(43.7)$ \\
\hline \multicolumn{5}{|l|}{ B } \\
\hline & 119 & $33(27.7)$ & $27(22.7)$ & $59(49.6)$ \\
\hline
\end{tabular}


TABLE 4.

The development of round pearl shapes $(R)$ in relation to the difference between the nucleus weight used for surgreffe and the harvested pearl weight from graft: DW (in g). Three variables are presented: (1) round shape (R); (2) oval shape (O); and (3) baroque shape (B), with their corresponding number and rate (\%) in brackets.

\begin{tabular}{|c|c|c|c|c|}
\hline & & \multicolumn{3}{|c|}{ WD class } \\
\hline & & $\begin{array}{c}\text { Smaller } \\
<0\end{array}$ & $\begin{array}{c}\text { Equivalent } \\
0-0.5\end{array}$ & $\begin{array}{c}\text { Larger } \\
>0.5\end{array}$ \\
\hline Graft & $\mathrm{R}$ & 10 & 65 & 69 \\
\hline Surgreffe & $\mathrm{R}$ & $3(30.0)$ & $19(29.2)$ & $23(33.3)$ \\
\hline Graft & $\mathrm{O}$ & 3 & 15 & 14 \\
\hline Surgreffe & $\mathrm{R}$ & $2(66.7)$ & 7 (46.7) & $5(35.7)$ \\
\hline Graft & $\mathrm{B}$ & 20 & 56 & 43 \\
\hline Surgreffe & $\mathrm{R}$ & $4(20.0)$ & $15(26.8)$ & $14(32.6)$ \\
\hline
\end{tabular}

heaviest pearls in comparison with the other families at graft (Ky et al. 2013). Thus, for families B and D, DD, and DW were small and therefore resulted in greater circle rates. The DD and DW classes may therefore influence circle formation and could be used as indicators at the production scale. Such indicators could probably be extended to the grafting stage, where correspondence between nucleus size and gonad size may influence the formation of circles. Further studies should be conducted on recipient oysters at graft to examine the relationship between nucleus and gonad size.

\section{Differences in Pearl Shape Between Graft and Surgreffe in Pinctada margaritifera}

Descriptive comparison between the corresponding surgreffe and graft experiments (Ky et al. 2013) revealed the following trends from graft to surgreffe: (1) "R" shape decreased by nearly $20 \%$; (2) "O" shape increased by nearly $12 \%$; and (3) "B" shape increased by nearly $7 \%$ (when considering all of the 380 pearls from surgreffe). For the same reason as stated for the pearl circle criteria, shape variations between graft and surgreffe could not be explained by grafter skill or seasonal influences, but mainly by the standardized second nucleus size (3.5 BU) inserted into the pearl sac.

Increasing the proportion of " $R$ "-shaped pearls is one of the main goals of all pearl farmers. Results of the present study show how some progress toward improvement could be made at surgreffe in Pinctada margaritifera. Usually, for shape considerations, grafters only perform a surgreffe if an " $R$ " shape is harvested after the initial graft. We confirmed that this was a "good rule", independently from DW classes (weight difference between the nucleus inserted for surgreffe and the harvested pearl from the graft). Indeed, oysters that produced 
" $R$ "-shaped pearls from the initial graft also tended to produce " $R$ "-shaped pearls from the surgreffe, as shown by the constant rate obtained regardless of the size difference between the inserted second nucleus and the volume of the pearl sac from which the first pearl was harvested. More importantly, even when an "O" shape was formed after the graft, an " $\mathrm{R}$ " shape could be formed after surgreffe if the second inserted nucleus was lighter (and therefore smaller) than the pearl harvested after the graft. Results revealed that the rate of " $\mathrm{R}$ " shape could be doubled by this approach, as opposed to using a larger second nucleus. The observation for "O" shapes must, however, be considered in the light of the low number of samples corresponding to this shape category $(n=32)$. By contrast, when " $\mathrm{B}$ " shapes were produced from the initial graft but " $R$ " shapes after surgreffe, the trend was in favor of inserting a larger second nucleus as this could increase the amount of " $\mathrm{R}$ " shape pearls to nearly $40 \%$. In contrast, using lighter second nuclei produced more " $\mathrm{B}$ "-shaped pearls. In this case, the tension/pressure made by the pearl sac on the second inserted nucleus may play a role in favor of " $R$ " shape production. As for the pearl circle trait, the relationship between the pearl sac and the size of the second nucleus can be determinant for the shape. Indeed, pearl shape variation was already known to be linked to the recipient oyster: a xenograft experiment using Pinctada maxima and P. margaritifera, demonstrated that the influence of the recipient on pearl shape is stronger than that of the donor oyster (McGinty et al. 2010, Jerry et al. 2012).

\section{CONCLUSION}

The results obtained here on the development of cultured pearls of different shapes and the presence or absence of circles after surgreffe disagree with the rule commonly applied in most Pinctada margaritifera pearl farms, according to which surgreffe operations should only be performed when grafts have produced uncircled round pearls. Indeed, for circled cultured pearl criteria, our main results clearly demonstrate that the surgreffe operation could be realized on oysters that previously produced CLs: (1) to obtain significant proportions of uncircled pearls; and (2) that this modification can be accentuated through the insertion of a larger surgreffe nucleus size (and weight) relative to the pearl harvested after the initial graft. In the case of pearl shape: (1) it was possible to obtain round pearls from surgreffe on animals that had produced baroque shape pearls after the initial graft; and (2) this was enhanced by inserting a larger surgreffe nucleus. Inserting a second nucleus larger than the pearl harvested after the graft, but limited in size to avoid ripping the pearl sac, will significantly increase the rate of both uncircled and round-shaped pearls at surgreffe. These findings have major implications for production on most pearl farms, where recipient oysters that have produced undesirable circled and baroque pearls would no longer be sacrificed, but used in surgreffe operations to increase productivity.

Further studies should be conducted to analyze the role played by the recipient oyster on pearl shape and particularly on pearl sac morphology at harvest time. Indeed, the close relationship between the surgreffe nucleus size/weight and the available volume in the pearl sac is the determinant for the development of pearl circles and shapes. As the size of the pearl sac is directly impacted by food availability (environment), gonadic status (season), incision area (grafter skill), and recipient morphology (shell biometry), the complex formation of circles and shapes must be studied through a multifactorial approach and attention paid to their correlation with other qualitative traits.

\section{ACKNOWLEDGMENTS}

This work was supported through grants from the Direction des Ressources Marines et Minières (Marché négocié 2013 to 2014). We would also especially like to thank the host site team at Gauguin's Pearl Farm (Rangiroa atoll, Tuamotu Archipelago, French Polynesia) for their generous assistance, especially the grafter Jacques Pavaouau, and the workers Laurent Shan and Bastiano Mare for the experimental surgreffe and pearl oyster culture maintenance.

\section{LITERATURE CITED}

Blay, C., M. Sham-Koua, V. Vonau, R. Tetamu, P. Cabral \& C. L. Ky. 2013. Influence of nacre deposition rate on cultured pearl grade and colour in the black-lipped pearl oyster Pinctada margaritifera using farmed donor families. Aqua. Inter. 22:937-953.

Cartwright, J. H. E., A. G. Checa \& M. Rousseau. 2013. Pearls are selforganized natural ratchets. Langmuir 39:8370-8376.

Cuif, J. P. \& Y. Dauphin. 1996. Occurrence of mineralization disturbances in nacreous layers of cultivated pearls produced by Pincatada margaritifera var. cumingi from French Polynesia. Comparison with reported shell alterations. Aquat. Living Resour. 9:187-193.

Dagnelie, P. 2007. Statistique théorique et appliquée, $3^{\text {rd }}$ edition. Bruxelles, Belgium: De Boeck Université.

Du Prel, A. 2012. Perliculteurs japonais. Tahiti Pacifique Magazine 258:10-12.

Haws, M. 2002. The basic methods of pearl farming: a layman's manual. Hawaii: Center for tropical and subtropical aquaculture publication. 127 pp.

Hutchinson, T. P. 1996. On the generalised friedman test. Comput. Stat. Data Anal. 21:473-476.

Inoue, N., R. Ishibashi, T. Ishikawa, T. Atsumi, H. Aoki \& A. Komaru. 2011. Gene expression patterns in the outer mantle epithelial cells associated with pearl sac formation. Mar. Biotechnol. (NY) 13:474-483.
Institut de la Statistique de Polynésie Française (ISPF). Available at: http://www.ispf.pf.

Ito, M. 2011. Circle and spot formation mechanisms and changes in luster, color, and roundness of cultured pearls by grafting methods in Pinctada margaritifera. Gems Gemnol. 47:148.

Jerry, D. R., R. Kvingedal, C. E. Lind, B. S. Evans, J. U. Taylor \& A. E. Safari. 2012. Donor oyster derived heritability estimates and the effect of genotype $\mathrm{x}$ environment interaction on the production of pearl quality traits in the silver-lip pearl oyster, Pinctada maxima. Aquaculture 338:66-71.

Kawakami, I. K. 1952. Studies on pearl-sac formation. On the regeneration and transplantation of the mantle piece in the pearl oyster. Mem. Fac. Kyushu Univ. 1:83-89.

Ky, C. L., C. Blay, M. Sham-Koua, V. Vanaa, C. Lo \& P. Cabral. 2013. Family effect on cultured pearl quality in black-lipped pearl oyster Pinctada margaritifera and insights for genetic improvement. Aquat. Living Resour. 26:133-145.

Ky, C. L., C. Blay, M. Sham-Koua, C. Lo \& P. Cabral. 2014a. Indirect improvement of pearl grade and shape in farmed Pinctada margaritifera by donor "oyster" selection for green pearls. Aquaculture 432:154-162.

Ky, C. L., S. Nakasai, N. Molinari \& D. Devaux. 2014b. Influence of grafter skill and season on cultured pearl shape, circles and rejects in 
Pinctada margaritifera aquaculture in Mangareva lagoon. Aquaculture 435:361-370.

Ky, C. L., S. Nakasai, N. Molinari \& D. Devaux. 2015. Influence of grafter skill and season on cultured pearl shape, circles and rejects in Pinctada margaritifera aquaculture in Mangareva lagoon. Aquaculture 435:361-370.

Lane, I., C. Oengpepa \& J. Bell. 2003. Production of grow-out of the black-lip pearl oyster Pinctada margaritifera. Aquaculture Asia 8:5-7.

Le Pennec, M. \& D. Buestel. 2010. Mythe et histoire de la nacre et de la perle, In: M. Le Pennec, editor. Huître perlière et perle de Tahiti. French Polynesia: HQImaging. 204 pp.

Machii, A. 1968. Histological studies on the pearl sac formation. Bull. Pearl Res. Lab. 13:1489-1539.

McGinty, E. L., B. S. Evans, J. U. U. Taylor \& D. R. Jerry. 2010. Xenografts and pearl production in two pearl oyster species, Pinctada maxima and P. margaritifera: effect on pearl quality and a key to understanding genetic contribution. Aquaculture 302:175-181.

Murzyniec-Laurendeau, S. 2002. La Perle de Tahiti: La fin de la Crise. Master of Advance Studies thesis, University of French Polynesia. 125 pp.
Sarikaya, M., J. Liu \& I. A. Aksay. 1995. Nacre: properties, crystallography, morphology, and formation. In: M. Sarikaya \& I. A. Aksay editors. Biomimetics: design and processing of materials. New York, NY: Woodbury. 35-90 pp.

Siegel, S. \& N. J. Castellan. 1988. Nonparametric statistics for the behavioral sciences, $2^{\text {nd }}$ edition. New York, NY: McGraw-Hill.

Strack, E. 2006. Pearls, Stuttgart, Germany: Rühle-Diebener-Verlag. 706 pp.

Talvard, C. 2011. La perliculture en 2010. Points Forts de la Polynésie Française. 10:8 pp.

Tayale, A., Y. Gueguen, C. Treguier, J. Le Grand, N. Cochennec-Laureau, C. Montagnani \& C. L. Ky. 2012. Evidence of donor effect on cultured pearl quality from a duplicated grafting experiment on Pinctada margaritifera using wild donors. Aquat. Living Resour. 25:269-280.

Taylor, J. \& E. Strack. 2008. Pearl production. In: P. C. Southgate \& J. S. Lucas, editor. The pearl oyster. Amsterdam, The Netherlands: Elsevier. pp. 273-302.

Wane, G. 2013. Les problèmes réels de l'industrie de la perle de Tahiti. Tahiti Pacifique, Mensuel d'information et d'économie 260:15-23. 